УДК 615.322

DOI: 10.18101/2306-1995-2019-2-38-43

\title{
ВЛИЯНИЕ КОМПЛЕКСНОГО СРЕДСТВА НА РЕЗИСТЕНТНОСТЬ ОРГАНИЗМА БЕЛЫХ КРЫС К ГИПОКСИЯМ РАЗЛИЧНОГО ГЕНЕЗА
}

\section{(C) Тишковец Светлана Валерьевна}

старший преподаватель, Медицинский институт, Бурятский государственный университет им. Д. Банзарова Россия, 670000, г. Улан-Удэ, ул. Октябрьская, 36а E-mail: tcb-amur@yandex.ru

\section{(C) Разуваева Янина Геннадьевна}

доктор биологических наук, старший научный сотрудник, Институт общей и экспериментальной биологии СО РАН Россия, 670047, г. Улан-Удэ, ул. Сахъянова, 6 E-mail: tatur75@mail.ru

\section{(C) Торопова Анюта Алексеевна}

кандидат биологических наук, научный сотрудник Институт общей и экспериментальной биологии СО РАН Россия, 670047, г. Улан-Удэ, ул. Сахьяновой, 6 E-mail: anyuta-tor@mail.ru

\section{(C) Нимаева Дарима Эдуардовна}

кандидат медицинских наук, заведующая эндокринологическим центром, РКБ имени Н. А. Семашко

Россия, 670031, г. Улан-Удэ, ул. Пирогова, 17a

E-mail: darima_nim@mail.ru

В опытах на белых крысах линии Wistar исследовали влияния экстракта сухого комплексного средства (Juglans regia L., Corylus avellana L., Agrimonia eupatoria L., Bidens tripartita L., Xanthium strumarium L., Urtica dioica L., Lemna minor L., Cichorium intybus L. и Onopordum acanthium L.) на резистентность организма белых крыс к гипоксиям различного генеза. Антигипоксическую активность фитосредства исследовали на 3 моделях: гиперкапническая, гемическая и гистотоксическая гипоксии. Экстракт сухой исследуемого средства в дозе 200 мг/кг вводили животным в течение 7 дней до моделирования гипоксии. В качестве препарата сравнения использовали препарат танакан в дозе 100 мг/кг. Установлено, что исследуемое средство обладает антигипоксическим действием, увеличивая продолжительность жизни животных при гипоксической, гемической и гистотоксической гипоксиях на $23-28 \%(\mathrm{p} \leq 0,05)$. Применение танакана повышало резервное время жизни белых крыс в среднем на $32 \%$ $(\mathrm{p} \leq 0,05)$.

Ключевые слова: комплексное растительное средство, гипоксия, антигипоксическая активность, белые крысы. 
C. В. Тишковеи и др. Влияние комплексного средства на резистентность организма белых крыс к гипоксиям различного генеза

Для цитирования:

Тишковец С. В., Разуваева Я. Г., Торопова А. А., Нимаева Д. Э. Влияние комплексного средства на резистентность организма белых крыс к гипоксиям различного генеза // Вестник Бурятского государственного университета. Медицина и фармация. 2019. Вып. 2. С. 38-43.

«Тиреофит» - условное название экстракта сухого, полученного путем экстракции растительной композиции - листья грецкого ореха (Juglans regia L.), листья лещины обыкновенной (Corylus avellana L.), листья репешка обыкновенного (Agrimonia eupatoria L.), трава череды трехраздельной (Bidens tripartita L.), трава дурнишника колючего (Xanthium strumarium L.), листья крапивы двудомной (Urtica dioica L.), трава ряски малой (Lemna minor L.), корни цикория обыкновенного (Cichorium intybus L.) и трава татарника колючего (Onopordum acanthium L.), широко используемых в народной медицине при лечении заболеваний щитовидной железы $[2,6]$. В экспериментах на животных установлено, что «Тиреофит» проявляет фармакотерапевтическую эффективность при мерказолиловом гипотиреозе, способствуя снижению содержания тиреотропного гормона, восстановлению уровня тиреодных гормонов, а также нормализации функционального состояния сердечнососудистой и нервной систем $[7,8,10]$. Испытуемое средство проявляет противовоспалительную, антиоксидантную и мембраностабилизирующую активность $[9,11]$.

Учитывая, что снижение эффективности тиреоидных гормонов при гипотиреозе приводит к торможению метаболизма с формированием гипоксии в клетках практически всех органов и тканей, актуальным является исследование антигипоксического действия фитоэкстракта «Тиреофит».

Целью исследования явилось определение влияния комплексного средства на резистентность организма белых крыс к гипоксиям различного генеза.

\section{Материалы и методы}

Эксперименты проведены на 72 крысах линии Wistar обоего пола с исходной массой 180-200 г. Содержание животных соответствовало «Правилам лабораторной практики (GLP) и Приказу МЗ РФ № 199Н от 01.04.2016 г. «Об утверждении Правил надлежащей лабораторной практики». Перед началом экспериментов животных, отвечающих критериям включения в эксперимент (пол, возраст, масса), распределяли на группы с учетом принципа рандомизации (случайности). Экспериментальную работу осуществляли в соответствии с «Правилами, принятыми в Европейской конвенции по защите позвоночных животных» [Страсбург, 1986]. 
Экстракт сухой «Тиреофит» в дозе 200 мг/кг вводили животным первой опытной группы в течение 7 дней, последнее введение осуществляли за 1 час до моделирования гипоксии. В качестве препарата сравнения использовали препарат танакан («Ipsen Pharma» Франция), представляющий собой стандартизированный экстракт из листьев Ginkgo biloba, который вводили животным второй опытной группы в дозе 100 мг/кг. Животные контрольной группы получали воду очищенную в эквивалентном объеме по аналогичной схеме. Антигипоксическую активность фитосредства исследовали на 3 моделях: гиперкапническая, гемическая и гистотоксическая гипоксии. Острую нормобарическую гипоксию с гиперкапнией моделировали помещением животных в гермокамеру объемом 1000 мл, где они находились до появления признаков терминальной стадии гипоксии: судороги, агональное дыхание, атония задних конечностей; острую гемическую гипоксию вызывали внутрибрюшинным введением нитропруссида натрия в дозе 20 мг/кг, острую гистотоксическую гипоксию - нитрита натрия в дозе 200 мг/кг [12]. Продолжительность жизни животных (резервное время) регистрировали по последнему агональному вдоху.

Статистическая обработка полученных результатов проводилась с помощью пакета программ «Biostat-2006» с использованием t-критерия Стьюдента. Различия между сравниваемыми группами считали статистически значимыми при $\mathrm{P} \leq 0,05$.

\section{Результаты и обсуждение}

Результаты исследований показали, что экстракт сухой «Тиреофит» проявляет антигипоксическую активность, увеличивая продолжительность жизни животных при гемической и нормобарической гипоксиях в среднем на $23 \%$, при гистотоксической гипоксии - на $28 \%$ по сравнению с показателями контрольных животных (рис. 1). При этом антигипоксическая активность исследуемого средства уступала таковой препарата сравнения - танакан, повышающего данный показатель на $32 \%, 28 \%$ и $34 \%$ соответственно по отношению к контролю. 
C. В. Тишковец и др. Влияние комплексного средства на резистентность организма белых крыс к гипоксиям различного генеза

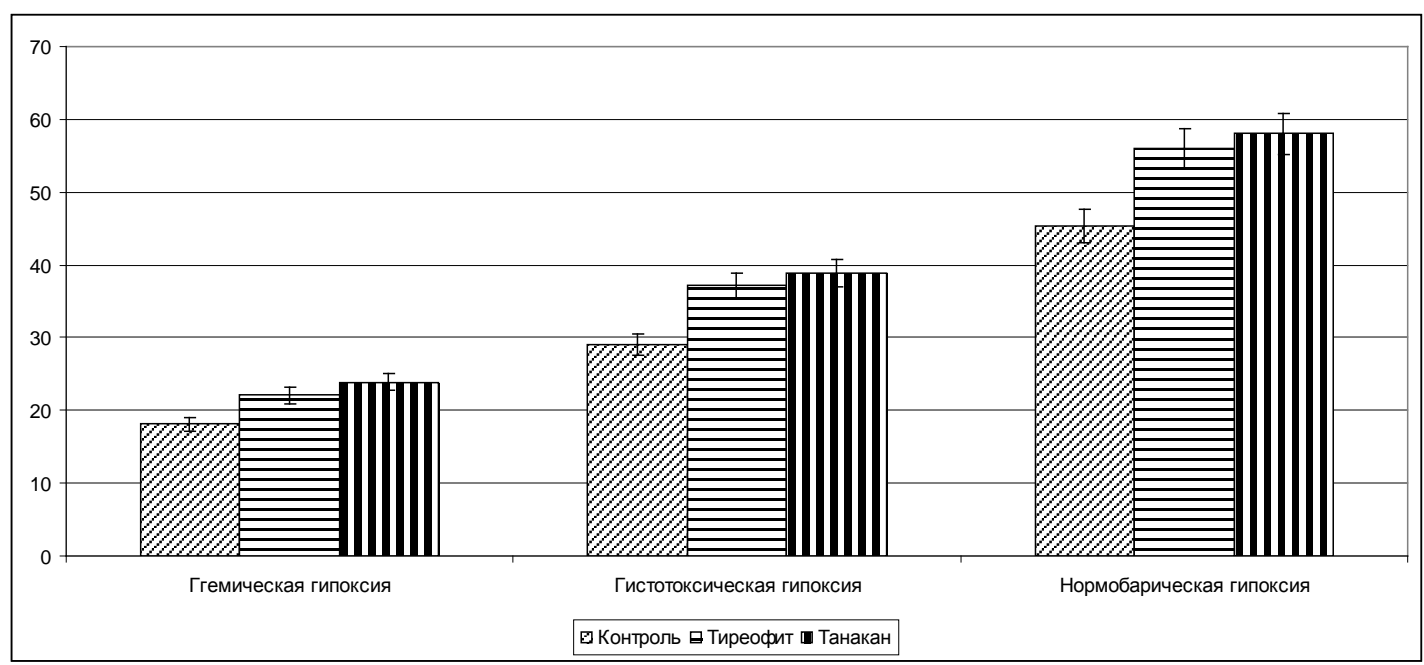

Рис. 1. Антигипоксическая активность комплексного растительного средства «Тиреофит»

Таким образом, «Тиреофит» обладает антигипоксической активностью, увеличивая продолжительность жизни животных на фоне гипоксий различного генеза, что обусловлено наличием в его составе: C. intybus [13], L. minor [1, 5], U. dioica [3, 4], обладающих стимулирующими и антигипоксическими свойствами.

Исследования проведены в рамках выполнения темы госзадания № АAАAA17-117011810037-0.

\section{Литература}

1. Фенольные соединения этанольных извлечений Lemna minor L., Lemna trisulca L. и Lemna polyrrhiza L. Schleid. и их иммуномодулирующая активность / С. М. Адекенов [и др.] // Бюллетень сибирской медицины. 2017. Т. 16, № 3. С. 5-15.

2. Алефиров А. Н. Фитотерапия заболеваний щитовидной железы. СПб., 2008. С. 312.

3. Определение гидроскикоричных кислот, каротиноидов и хлорофилла в листьях крапивы двудомной (Urtica dioica L.) Сафонова / О. В. Гринеева [и др.] // Химия растительного сырья. 2015. № 3. С. 105-110.

4. Лесиовская Е. Е., Пастушенков Л. В. Фармакотерапия с основами фитотерапии. М., 2003. 592 с.

5. Сравнительное исследование веществ первичного обмена ряски малой (Lemna minor L.), ряски тройчатой (Lemna trisulca L.) и многокоренника обыкновенного (Spirodella polyrrhiza L. Schleid.) / Л. А. Никифоров [и др.] // Бюллетень сибирской медицины. 2017. Т. 16, № 1. С. 59-64.

6. Перспективы использования фитопрепаратов в современной медицине / Т. В. Самбукова [и др.] // Обзоры по клинической фармакологии и лекарственной терапии. 2017. Т. 15, № 2. С. 56-63. 
7. Влияние комплексного растительного средства на функциональное состояние щитовидной железы белых крыс при экспериментальном гипотиреозе / С. В. Тишковец [и др.] // Новые и нетрадиционные растения и перспективы их использования: материалы XII Междунар. симпоз. М., 2017. С. 78-82.

8. Фитокоррекция нарушений гормонального статуса и показателей сердечно-сосудистой системы у белых крыс при экспериментальном гипотиреозе / С. В. Тишковец [и др.] // Курортная база и природные лечебнооздоровительные местности Тувы и сопредельных регионов: материалы III Междунар. науч-практ. конф. Кызыл, 2017. С. 101-104.

9. Противовоспалительная активность комплексного растительного средства / С. В. Тишковец [и др.] // Якутский медицинский журнал. 2018. T. 3(63). C. 22-25.

10. Фитокоррекция нарушений когнитивных функций у белых крыс при экспериментальном гипотиреозе / С. В. Тишковец [и др.] // Наука и инновация (Душанбе). 2018. № 1. С. 200-205.

11. Исследование мембраностабилизирующей и антиоксидантной активности фитосредства в условиях in vitro / С. В. Тишковец [и др.] // Вопросы биологической, медицинской и фармацевтической химии. 2019. № 1. C. 27-33.

12. Хабриев Р. У. Руководство по экспериментальному (доклиническому) изучению новых фармакологических веществ. М., 2012. $832 \mathrm{c}$.

13. Abbasa Z. K., Saggua S. et al. Phytochemical, antioxidant and mineral composition of hydroalcoholic extract of chicory (Cichorium intybus L.) // Saudi Journal of Biological Sciences. 2015. V. 22, № 3. P. 322-326. 
C. В. Тишковеи и др. Влияние комплексного средства на резистентность организма белых крыс к гипоксиям различного генеза

\section{THE EFFECT OF THE COMPLEX REMEDY ON THE RESISTANCE OF THE ORGANISM OF WHITE RATS TO HYPOXIA OF VARIOUS GENESIS}

\section{Svetlana $V$. Tishkovets}

Senior Lecturer of Medical Institute, Medical Institute, Dorzhi Banzarov Buryat State University

36a, Oktyabrskaya st., Ulan-Ude, 670001, Russia

E-mail: tcb-amur@yandex.ru

\section{Yanina G. Razuvaeva}

Doctor of biological sciences, Senior Research Scientist of the Laboratory of Biologically Active Substances Safety of the Institute of General and Experimental Biology SB RAS.

6, Sakhyanova st., Ulan-Ude, 670047, Russia

E-mail: tatur75@mail.ru

Anyuta A. Toropova

Candidate of biological sciences, Research Scientist of the Laboratory of Biologically Active Substances Safety of the Institute of General and Experimental Biology SB RAS, 6, Sakhyanova st., Ulan-Ude, 670047, Russia

E-mail: anyuta — tor @mail.ru

\section{Darima E. Nimaeva}

Candidate of Medical sciences,

Republican Clinical Hospital N. A. Semashko, 17 a, Pirogova st., Ulan-Ude, 670031, Russia

The antihypoxic effect of the complex herbal remedy «Tireofit» as studied in experiments on white Wistar rats. The «Tireofit» demonstrated antihypoxic effect at the dose $200 \mathrm{mg} / \mathrm{kg}$ increasing lifespan of animals in hypercapnic, hemic and histotoxic hypoxias.

Keywords: complex herbal remedy, hypoxia, antihypoxic activity, hypoxia, white rats 